\title{
Composition and rheological characteristics of plaster mixtures
}

\author{
Marat Asamatdinov ${ }^{1}$, Ekaterina Shokodko ${ }^{1}$, Andrey Ushakov ${ }^{1}$, Igor Bessonov ${ }^{2}$, Sergey \\ Kozlov ${ }^{1}$ and Artem Zhukov ${ }^{1}$ \\ ${ }^{1}$ Moscow State University of Civil Engineering, Yaroslavskoe Shosse, 26, Moscow, 129337, Russia \\ ${ }^{2}$ Research Institute of Building Physics of the Russian Academy of Architecture and Building \\ Sciences, Lokomotivniy Tr., 21, Moscow, 127238, Russia
}

\begin{abstract}
The applying of local building materials is an effective contribution to the savings of mineral resources, which are used for the production of basic building materials. Clay and gypsum compositions are the local raw materials in many regions of the country and some neighboring countries. The article discusses the method for determining the clay fraction in the clay and gypsum composition, as well as the method for assessing the rheological characteristics of the plaster mixtures for interior work based on clay and gypsum binder. It was established that the content of the clay fraction in the studied clay and gypsum composition is in the range of 30-32\%. Plaster mixtures based on clay and gypsum binder can be considered as optimal compositions under the following conditions. The grade of mobility is not less than $\mathrm{P}_{\mathrm{K}} 3(8-12 \mathrm{~cm})$ in cone penetration test, the ultimate shear stresses in the first seconds of the thixotropic hardening ensure no runoff for the adjusted thickness of the applied layer. With the mentioned mobility, the "creeping" on the concrete surface is $10 \%$ and less, and the "creeping" on the brick surface is no more than $5 \%$. The allowable water-solid ratio is $0,46-0,50$.
\end{abstract}

\section{Introduction}

Clay and gypsum compositions can be considered as natural building composites since they are a relatively dense conglomerate consisting of the calcium sulfate dihydrate (gypsum), the clay minerals, the silica, and other impurities. A complex of modifying additives is added into the composition of the clay and gypsum binder, as well as into the plaster dry building mixtures. The applying of additives allows you to adjust the properties of clay and gypsum systems and makes possible the occurrence of synergistic effects, which must be confirmed experimentally [1-5].

A lot of Soviet researchers in the 40s and 70s of the twentieth century were studying the properties of clay and gypsum binders and the possibility of their use in the construction. Based on the works of a number of authors (N.S. Bogdanov, L.A. Zakharov, K.S. Kutateladze, M.Z. Simonov, B.S. Ziegler, A.M. Tkeshelashvili, etc.) it was found that, on

\footnotetext{
* Coresponding author: bezuglova-e@inbox.ru
} 
the basis of clay and gypsum composition, it is possible to obtain a gypsum binder with various properties. However, the industrial application of the

clay and gypsum binder was never established. After the 70s of the last century, no studies of the clay and gypsum composition have been conducted [6-10].

Clay and gypsum binder is not used due to low level of knowledge of the technology of its production and further use. The main problem is its particular composition (unstable gypsum content and high content of impurities in some deposits). The development of the effective clay and gypsum binders is the issue of creating of the scientifically based methods for raw materials processing and obtaining of modified gypsum binder for various building mortars, first of all, plaster compositions [11-14].

\section{Methods}

The necessity to develop a methodology for determining the compound of the clay and gypsum binder has become the target basis of the research. The using of the thermal methods for studying the clay and gypsum composition was impossible. The thermal exposure resulted in dehydration of both dihydrate gypsum and clay minerals, which distorted the test result. The study of the rheological parameters of clay and gypsum mixtures and, in particular, the process of their "non-slipping" after applying to the mineral surface, ensured good adhesion of the clay-gypsum plaster to the surface of various types.

The article presents a study of the compound of natural clay and gypsum binder, as well as research the rheology of these compositions and their thixotropic properties. The methodology for assessing the compound of the binder, the additional requirements for the characteristics of the dry building mixtures based on the clay and gypsum binder, the requirements for the application of the dry building mixtures, as well as the methodology for verifying these requirements under laboratory conditions are presented.

The main problem when performing plastering work on vertical surfaces is a preliminary determination of the absence of runoff (slipping) of mortar mixes at various thickness of the applied layer. The assessment of such technological factors is implemented empirically [15-18]. A theoretical design solution is possible and based on the formula:

$$
\tau \geq 4 \rho \delta
$$

$\tau$ - ultimate shear stress (provided that it exceeds the adhesive strength of the plaster layer); $\rho$ - plaster density; $\delta$ - layer thickness.

The indicator of the properties of plaster compositions, defined as "runoff", characterizes the creep of mortar mixes in thick layers on vertical surfaces. This can be modeled by applying a cylindrical layer using a metal cylinder of a determined height (Fig. 1). A numerical indicator here can be the value of displacement of the lower end of a cylinder prepared from a mortar mixture. In plaster compositions corresponding to the zero "run-off" indicator, the cylinder-displacement should not exceed 0.5 layer thickness during 10 seconds in a vertical position.

On the vertical plane (see Figure 1), the plaster mortar mixture is acted upon by the force of gravity $\left(\mathrm{F}_{\mathrm{G}}\right)$ and the force of adhesion to the base $\left(\mathrm{F}_{\mathrm{F}}\right)$. Gravity tends to move down and rotate the mortar mixture - its value is proportional to the layer thickness and density of the mortar mixture. The force of adhesion of the mortar mixture to shear can be estimated by the shear stress (as a first approximation). In this case, the equilibrium shear condition can be written in formula:

$$
\begin{array}{r}
k \tau_{s} S \geq \rho \delta S \\
k \tau_{s} \geq \rho \delta
\end{array}
$$


$k$ - shear slip coefficient; $\tau_{\mathrm{s}}$ - ultimate shear stress, $\rho$ - density, $\delta$ - thickness, $S$ - contact area.

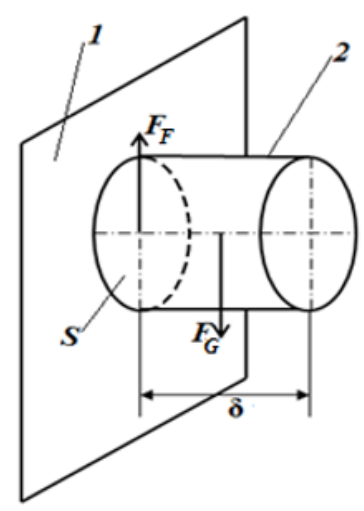

Fig. 1. Forces acting on a plaster mortar layer on a vertical surface: 1 - plastered surface; $2-$ fragment of a layer of plaster; $S$ - contact area of the surface and plaster mix; $F_{\mathrm{F}}$ - friction force (adhesion of the mixture to the surface); $F_{\mathrm{G}^{-}}$the force of gravity.

The ultimate shear stress $\tau_{\mathrm{sd}}$ is determined at the conical plastomere (Rebinder cone) or at the reference cone according to GOST 5802-2018 "Building solutions. Test methods "(Figure 2). The calculation is carried out according to the formula:

$$
\tau_{s}=K_{a} \frac{F}{h_{k}^{2}}
$$

$F$ - force acting on the mortar mixture; $\mathrm{h}_{\mathrm{k}}$ - cone penetration depth; $K_{\alpha}=\frac{1}{\pi} \cos \frac{\alpha}{2} \operatorname{ctg} \frac{\alpha}{2}$ cone constant depending on vertex angle; when $\alpha$ is $30 ; 45 ; 60$ degrees, cone constant is equal respectively 1,$107 ; 0,568 ; 0,413$.

The thixotropic properties were assessed by the increase in ultimate shear stresses at rest. For plaster compositions based on clay and gypsum binder, the shear stress in the first seconds was a calculated value (instant tixotropy). It has been established that a further increase in shear stresses does not significantly affect the runoff process, and the high speed of thixotropic structure formation in the rest period of 5-10 minutes may even complicate the process of leveling of plaster.

Prior to the measurement of the ultimate shear stress and runoff process, the thixotropic structure of plaster mixtures was extremely destroyed in a high-speed mixer $(400 \div 500$ $\mathrm{rpm})$. Evaluation of the thixotropic properties of mortars based on gypsum binders is difficult due to the fact that the processes of thixotropic hardening and hydration of the binder proceed simultaneously. However, in the time period of 1-10 seconds after the ultimate destruction of the structure of the mortar mixture, the process of hydration of the binder can be ignored due to the slow increase in strength.

Experimental evaluation of additional requirements for plaster compositions based on clay and gypsum binder in laboratory conditions was carried out as follows. To estimate the runoff, the cylinder is taken whose height corresponds to the maximum thickness of the applied layer. The internal surface of the cylinder is lubricated with engine oil. The cylinder is placed on a horizontally mounted concrete slab and filled with a mortar mixture with the grade of mobility of $\mathrm{Pk}_{3}(8-12 \mathrm{~cm})$. Cylinder is gently lifted up and set aside. Concrete slab is set vertically (Figure 2). 
Within 1 and 10 seconds, it is estimated the displacement of the lower end of the cylindrical shape of the sample relative to the initial position. It is considered that there is no runoff if the outer lower end of the cylinder has shifted by no more than $50 \%$ of the layer thickness.

At the same time, the ultimate shear stress at the reference cone is estimated. Before measurement in both cases, the thixotropic structure of the mortar mixture is extremely destroyed.
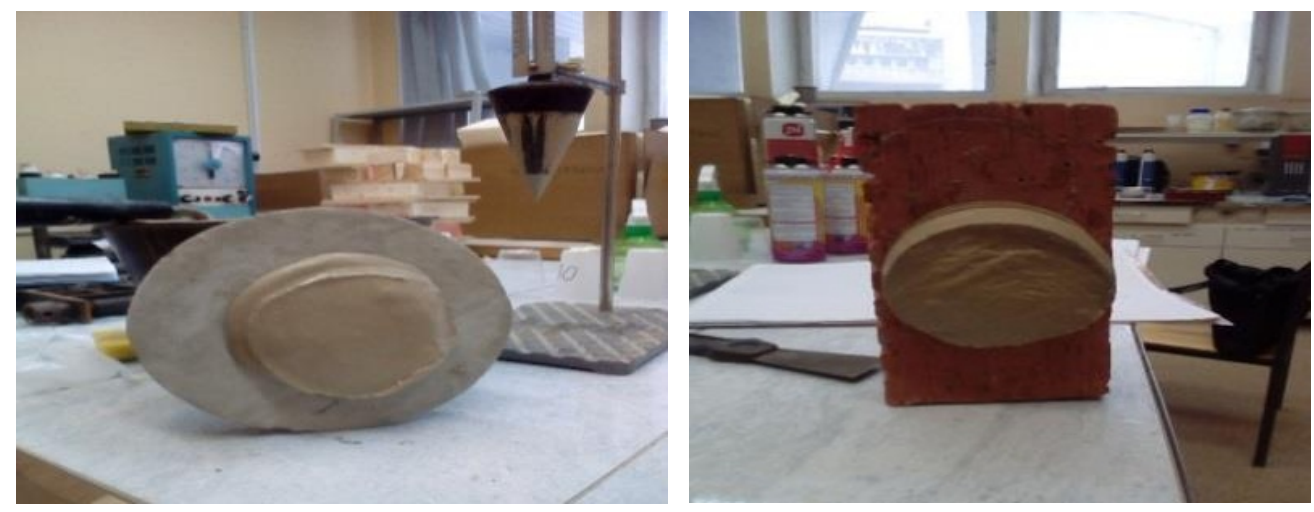

Fig. 2. Evaluation of the runoff of the plaster mix from the base.

\section{Results}

The determination of the content of dust and clay fractions was carried out by the method of decantation. It was found that $38.7 \%$ of the dust and clay particles were decanted after 2 hours of soaking; $43.8 \%$ of dust and clay particles were decanted after 24 hours of soaking of clay and gypsum binder. Evaluation of the composition of the decanted fraction showed that the compound is $1 / 3$ of finely silica and $2 / 3$ of the clay part. The content of clay particles in clay and gypsum binder was estimated at $28-30 \%$.

Plaster compositions based on clay and gypsum binder were used for testing on determining of the "runoff" characteristics. The results of the experiments are presented in the table.1.

Table 1. The results of experiments on determining of the "runoff" characteristics of the plaster mortar mixes with the layer thickness of $20 \mathrm{~mm}$.

\begin{tabular}{|c|c|c|c|c|}
\hline $\begin{array}{c}\text { Water-solid } \\
\text { ratio, } \\
\text { W/S }\end{array}$ & $\begin{array}{c}\text { Density } \rho, \\
\mathrm{g} / \mathrm{cm}^{3}\end{array}$ & \multicolumn{2}{|c|}{$\begin{array}{c}\text { Ultimate shear stress, } \\
\mathrm{g} / \mathrm{cm}^{2}\end{array}$} & $\begin{array}{c}\text { Shift of the } \\
\text { bottom end } \Delta \text { in } \\
10 \text { seconds, } \\
\mathrm{mm}\end{array}$ \\
\cline { 3 - 5 } & & $\tau_{\mathrm{S}} 1, \mathrm{c}$ & $\tau_{\mathrm{S}} 10, \mathrm{c}$ & $0^{\mathrm{a}}$ \\
\hline 0,46 & 1,51 & 4,7 & 4,9 & $6^{\mathrm{a}}$ \\
\hline 0,48 & 1,42 & 4,2 & 4,3 & $9^{\mathrm{a}}$ \\
\hline 0,50 & 1,40 & 3,9 & 4,1 & 13 \\
\hline 0,52 & 1,40 & 3,5 & 3,9 & 13 \\
\hline
\end{tabular}

${ }^{a} \Delta$ corresponds the condition "no runoff"

For ${ }^{\mathrm{a}} \Delta$ values in the formula (3) coefficient $\mathrm{k}$ can be taken equal to one, then: $\tau_{s} \geq \rho \delta$

In order to select the optimal composition of plaster mixtures, tests were carried out to determine the effect of various parameters on the thixotropic properties of the mixtures (Figure 3). The influence of the water-solid ratio on the rheological behavior of the plaster mixture based on the clay and gypsum binder was investigated. 


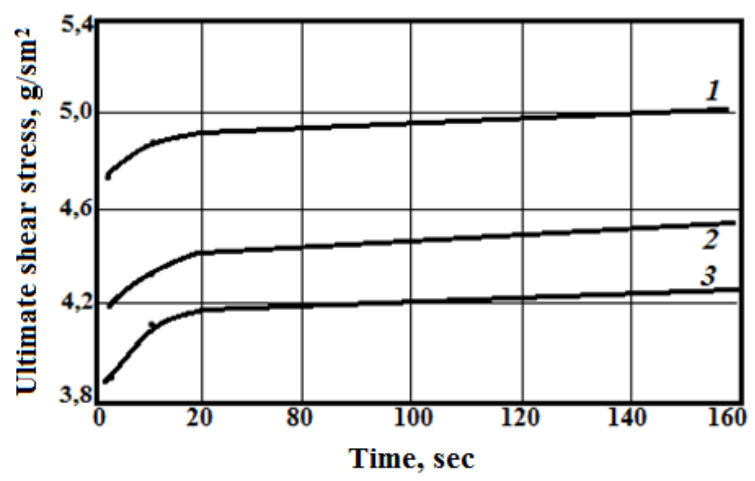

Fig. 3. The influence of the water-solid ratio (W/S) on the thixotropic properties: $1-\mathrm{W} / \mathrm{S}$ is 0,52 ; $2-\mathrm{W} / \mathrm{S}$ is 0,$48 ; 3-\mathrm{W} / \mathrm{S}$ is 0,46 .

\section{Discussion}

Plaster mixtures based on clay and gypsum binder can be considered as optimal compositions under the following conditions. The grade of mobility is not less than $\mathrm{P}_{\mathrm{K}} 3$ (8$12 \mathrm{~cm}$ ) in cone penetration test, the ultimate shear stresses in the first seconds of the thixotropic hardening ensure no runoff for the stated thickness of the applied layer in one pass. With mentioned mobility the "creeping" on the concrete surface is $10 \%$ and less, and the "creeping" on the brick surface is no more than 5\%. It depends on the density, roughness, absorption capacity, humidity, degree of pollution, etc.

Other parameters of the hardened mortar (adhesion, compressive strength, tensile and flexural strength, crack resistance, frost resistance, vapor permeability, etc.) must correspond the regulations.

\section{Conclusion}

The clay and gypsum binder can be used as the basis of plaster compositions. There are significant reserves of raw materials, but it is not used on an industrial scale. The most important reason is the absence of a scientifically based theory of the hardening of the clay and gypsum binder and the formation of its properties with modifying additives and without additives. The research confirms the possibility of using the clay and gypsum binder in the composition of dry plaster mixtures for interior decoration works.

The research has presented that the water-solid ratio has a significant effect on the thixotropic properties of plaster mortars based on clay and gypsum binder. Accordingly, the modulation of the thixotropic properties of the mortar is carried out by changing the watersolid ratio within the limits allowed by the standards, in the interval $\mathrm{W} / \mathrm{S}=0.46-0.50$.

The study on the use of plaster mixtures based on clay and gypsum binder in the interior decoration of buildings were implemented in accordance with the contract № R.559-17 between NRU MGSU and TEPOFOL LLC dated on 15 September 2017 "The study of the physical and mechanical characteristics of "Tepofol" folded polyethylene in systems of exterior and interior insulation". 


\section{References}

1. P.M. Zhuk, A.D. Zhukov, Eco. and ind. in Russia 4, V22, 52-57 (2018)

2. M-B.K. Kodzoev, S.L. Isachenko, S.A. Kosarev, A.V. Basova, A.V. Skvortzov, M.O. Asamatdinov, A.D. Zhukov, MATEC Web of Conf. 170, 03022 (2018)

3. B.M. Rumyantsev, Technology of decorative acoustic materials (Moscow: MGSU, 2010)

4. V.F. Korovyakov, Proc. All-Russia Sem. Improving the efficiency of production and use of gypsum materials and products, 51-56 (Moscow: RAACS, 2002)

5. I.V. Bessonov Proc. All-Russia Sem. Improving the efficiency of production and use of gypsum materials and products, 82-87 (Moscow: RAACS, 2002)

6. A.D. Zhukov, V.F. Korovyakov, M.O. Asamatdinov, A.S. Chkunin, G.B. Rumyantsev, Sci Review 7, 86-90 (2016)

7. V.I. Telichenko, D.V. Oreshkin, Ecol. of urb. terr. 2, 31-33 (2015)

8. B.M. Rumyantsev, A.D. Zhukov, D.B. Zelenshikov, A.S. Chkunin, K.K. Ivanov, Yu.V. Sazonova, MATEC Web of Conf. 86, 04027 (2016)

9. A.D. Zhukov, M.O. Asamatdinov, A.S. Chkunin, K.K. Ivanov, G.B. Rumyantsev, Innovations in life 4(19), 35-43 (2016)

10. A.D. Zhukov, V.F. Korovyakov, T.A. Naumova, M.O. Asamatdinov, Sci Rev 1098 $101(2015)$

11. A.D. Zhukov, V.F. Korovyakov , M.O. Asamatdinov, Innovations in life 1(20), 104113 (2017)

12. A.D. Zhukov, V.F. Korovyakov, M.O. Asamatdinov, A.S. Chkunin, G.B. Rumyantsev, Sci Review 7, 86-90 (2016)

13. A.D. Zhukov, E.Yu. Bobrova, D.B. Zelenshchikov, R.M. Mustafaev, A.O. Khimich, Adv. Mater., Str. and Mec. Eng. 1025 - 1026, 1031-1034 (2014)

14. B.M. Rumyantsev, A.D. Zhukov, Internet-Bulletin VolgGASU 3(23) (2012)

15. H. Ross, F. Stahl, Plaster. Practical guide: materials, technology work, the prevention of defects ed. P.V. Zozulya (St. Petersburg: RIA "Quintet", 2006)

16. V.V. Kozlov, Dry building mixes (Moscow: The Association of Building Institutions, 2000)

17. E.R. Pyataev, A.S. Pilipenko, M.A. Burtseva, E.A. Mednikova, A.D. Zhukov, Mater. Sci. Eng. 365, 032015 (2018)

18. M.O. Asamatdinov, A.A. Medvedev, A.D. Zhukov, E.V. Zarmanyan , A.I. Poserenin, MATEC Web of Conferences 193, 03045 (2018) 